\title{
Śmiertelne zatrucie solą kuchenną - opis przypadku
}

\author{
Fatal salt poisoning - a case report
}

\author{
Barbara Potocka-Banaś ${ }^{凶}$, Sławomir Majdanik², Tomasz Banaśs ${ }^{3}$ Krzysztof Borowiak \\ 1 Pomorski Uniwersytet Medyczny w Szczecinie, Zakład Toksykologii Klinicznej i Sądowej, al. Powstańców Wlkp. 72, 70-111 Szczecin \\ 2 Pomorski Uniwersytet Medyczny w Szczecinie, Zakład Medycyny Sądowej, al. Powstańców Wlkp. 72, 70-111 Szczecin \\ ${ }^{3}$ Sąd Rejonowy Szczecin-Centrum w Szczecinie, ul. Kaszubska 42, 70-952 Szczecin \\ $\triangle$ bpotocka@pum.edu.pl
}

\begin{abstract}
Introduction: Salt ( $\mathrm{NaCl}$ ) is a chemical compound widely used in everyday life and in a number of medical procedures.

Case report: The paper presents a case of unintentional fatal poisoning with saltwater, resulting from improperly provided first aid in a subject who attempted suicide (overdose of medication), and consulted by forensic experts for potential medical malpractice. A 34-year-old woman drank about 10 glasses of water $(2500 \mathrm{~mL})$ with a significant amount of salt. There was no subsequent vomiting, but at first severe water-electrolyte
\end{abstract}

imbalance (severe hypernatremia) occurred and, consequently, multiple intracranial haematomas formed, ultimately leading to death.

Conclusion: This case illustrates the still existing lack of adequate awareness of the causes and consequences of severe waterelectrolyte imbalance which may result from incorrect attempts to treat acute poisoning.

Keywords: sodium chloride; poisoning; hypernatremia; waterelectrolyte imbalance.

\begin{abstract}
ABSTRAKT
Wstęp: Sól kuchenna ( $\mathrm{NaCl}$ ) jest związkiem chemicznym powszechnie wykorzystywanym zarówno w życiu codziennym, jak i w określonych procedurach medycznych.

Opis przypadku: W pracy przedstawiono opiniowany pod kątem popełnienia błędu lekarskiego przypadek niezamierzonego śmiertelnego zatrucia roztworem soli kuchennej, które było następstwem niefachowo udzielanej pomocy przedmedycznej osobie po podjętej przez nią próbie samobójczej (spożycie leków). W konsekwencji wypicia przez 34-letnią kobietę ok. 10 szklanek
\end{abstract}

wody ze znaczną ilością soli i braku późniejszych wymiotów najpierw doszło do ciężkich zaburzeń gospodarki wodno-elektrolitowej (ostra hipernatremia), a następnie wystąpiły mnogie krwiaki wewnątrzczaszkowe prowadzące ostatecznie do zgonu. Wniosek: Opisany przypadek wskazuje na wciąż istniejący brak należytej świadomości w kwestii przyczyn i następstw ostrych zaburzeń gospodarki wodno-elektrolitowej, jakie mogą być skutkiem błędnych prób leczenia ostrych zatruć.

Słowa kluczowe: chlorek sodu; zatrucie; hipernatremia; zaburzenia wodno-elektrolitowe.

\section{WSTĘP}

Sól kuchenna ( $\mathrm{NaCl}$ ) jest prostym związkiem chemicznym tworzącym w przyrodzie pokłady soli kamiennej oraz występującym w postaci rozpuszczonej w wodzie morskiej i w wodach mineralnych. Występuje również w organizmach żywych, m.in. w płynie pozakomórkowym. Jony $\mathrm{Na}^{+} \mathrm{i} \mathrm{Cl}^{-}$odgrywają kluczową rolę $w$ wielu procesach fizjologicznych, np. w regulacji gospodarki wodnej, utrzymywaniu stałego ciśnienia tętniczego czy funkcjonowaniu układu nerwowego. W medycynie 0,9\% roztwór $\mathrm{NaCl}$ (sól fizjologiczna) stosowany jest jako płyn infuzyjny. W latach 60. XX w. podręczniki medyczne zalecały stosowanie wodnych roztworów soli kuchennej w celu wywołania wymiotów. Jednak bardzo szybko dostrzeżono zagrożenia wynikające z takiego postępowania, a po opisaniu kilku przypadków śmiertelnych odstąpiono od tej procedury $[1,2]$.

Pomimo wielu zagrożeń wynikających z przedawkowania roztworów soli kuchennej są one nadal chętnie stosowane w warunkach domowych jako skuteczne i bezpieczne środki wymiotne [3].

W pracy przedstawiono, opiniowany pod kątem możliwości popełnienia błędu lekarskiego, przypadek niezamierzonego śmiertelnego zatrucia roztworem soli kuchennej będącego następstwem niefachowo udzielonej pomocy przedmedycznej.

\section{OPIS PRZYPADKU}

Z dokumentacji medycznej wiadomo, że w nocy ok. godz. 23.40 zespół karetki pogotowia ratunkowego został wezwany do 34-letniej kobiety, która ok. 1,5-2 godz. wcześniej wypiła alkohol i zażyła 12 tabletek preparatu Ketonal forte (ketoprofen, $100 \mathrm{mg}$ ). Pacjentka była przytomna, nieco posypiająca, odpowiadała na pytania. W celu sprowokowania wymiotów wypiła ok. 10 szklanek wody z solą (dokładna dawka soli nie została podana), jednak nie wymiotowała. W badaniu lekarz 
karetki pogotowia ratunkowego stwierdził czynność serca miarową, tony czyste, ciśnienie tętnicze krwi - 150/90 mmHg, częstość tętna - 83/min, częstość oddechu - 25/min, saturacja $\mathrm{O}_{2}-97$, poziom glukozy - $163 \mathrm{mg} \%$. Świadomość w skali Glasgow oceniono na 14 pkt. Brzuch był miękki. Pacjentce podano 3 tabletki preparatu Ranigast (ranitydyna, $150 \mathrm{mg}$ ), zalecono leżenie, wypoczynek i opiekę rodziny, a w razie bólów nadbrzusza gastroskopię.

Około 3 godz. później (4,5-5 godz. od zatrucia, o godz. 3.00) zespół pogotowia ratunkowego ponownie interweniował, ponieważ stan chorej się pogarszał, wystąpiła biegunka, chora straciła przytomność, po czym nastąpił napad drgawek. W badaniu lekarskim stwierdzono, że chora była przytomna, posypiająca, na pytania odpowiadała leniwie lub wcale, otwierała oczy. Pacjentka była wydolna krążeniowo i oddechowo, źrenice miała równe. Objawów oponowych, objawów piramidowych (np. objawu Babińskiego) czy drgawek nie stwierdzono. Ciśnienie tętnicze krwi wynosiło 150/100 mmHg, częstość tętna - 102/min, częstość oddechu - 30/min, saturacja $\mathrm{O}_{2}-94$. Świadomość w skali Glasgow oceniono na 12 pkt. Podano 2 ampułki leku klonazepamu. Zalecono wypoczynek, a rano wizytę u lekarza rodzinnego oraz konsultację neurologiczną. Jako przyczynę stanu pacjentki lekarz przyjął prawdopodobny wpływ leku ketoprofen i jego działań niepożądanych, jakie mogą pojawiać się w przypadku przedawkowania (np. splątanie, senność, zaburzenia świadomości, zawroty głowy, a nawet drgawki).

W dniu następnym po godz. 9 rano rodzina wraz z nieprzytomną pacjentką udała się do lekarza rodzinnego. $\mathrm{Z}$ wywiadu wynika, że napady drgawkowe powtarzały się wówczas u kobiety co ok. 7 min. Lekarz rodzinny po zbadaniu chorej postanowił nie przenosić jej z samochodu do przychodni, po czym wezwał zespół pogotowia ratunkowego.

Dwie godziny później (ok. 15-15,5 godz. od zatrucia) do chorej przyjechał zespół pogotowia ratunkowego. W badaniu lekarskim odnotowano epizod drgawkowy. Chora była nieprzytomna, a źrenice miała sztywne i równe. Świadomość w skali Glasgow oceniono na 3 pkt. Objawy oponowe i objaw Babińskiego były ujemne. Ciśnienie tętnicze krwi wynosiło 114/70 mmHg, częstość tętna - 123/min, częstość oddechu-20/min, saturacja $\mathrm{O}_{2}-83$. Podano dożylnie leki z grupy benzodiazepin (klonazepam i diazepam), po czym chorą przewieziono na szpitalny oddział ratunkowy.

Przy przyjęciu w warunkach szpitalnego oddziału ratunkowego wykonano w trybie pilnym badanie tomografii komputerowej głowy (TK), w którym stwierdzono:

- w prawej półkuli mózgu, w okolicy skroniowej kilka nieregularnych ognisk hiperdensyjnych o charakterze krwiaków śródmózgowych otoczonych hipodensyjną strefą obrzęku lub hemolizy (największy miał wymiary $35 \times 40 \times 50 \mathrm{~mm}$ ),

- obecność zmian hiperdensyjnych o charakterze wynaczynionej krwi w przestrzeniach podpajęczych podstawy czaszki (zbiornikach podstawy), nad prawą półkulą mózgu w okolicach czołowej, skroniowej i ciemieniowej oraz nad lewą półkulą mózgu w okolicach czołowej i ciemieniowej, a także od przodu w okolicy przysierpowej,
- poszerzenie przestrzeni przymózgowej do $4 \mathrm{~mm} \mathrm{w}$ okolicy czołowej nad prawą półkulą mózgu, zwężenie bruzd i szczelin prawej półkuli mózgu, ucisk na prawą komorę boczną mózgu i efekt masy w postaci przemieszczenia struktur środkowych mózgu z prawa na lewo o mniej więcej $5 \mathrm{~mm}$ (tj. wklinowanie pod sierp mózgu).

Po wykonaniu badań równowagi kwasowo-zasadowej stwierdzono kwasicę metaboliczną z pH 7,071; $\mathrm{pCO}_{2}$ 42,1 mmHg; $\mathrm{HCO}_{3} 11,7 \mathrm{mmol} / \mathrm{L} ; \mathrm{BE}-16,5 \mathrm{mmol} / \mathrm{L}$. Zlecono także oznaczenie alkoholu etylowego, które wynosiło 0,09\%o (stężenie „fizjologiczne", prawnie dopuszczalne). Laboratorium nie miało możliwości aparaturowych do oznaczenia stężenia leku ketoprofenu. W badaniach biochemicznych odchylenia stwierdzono w stężeniach sodu i potasu w surowicy, które wynosiły odpowiednio $182 \mathrm{mmol} / \mathrm{L}$ (norma 135-147 mmol/L) oraz 3,37 mmol/L (norma 3,7-5,3 mmol/L). Powtórny jonogram wykazał stężenie sodu $184 \mathrm{mmol} / \mathrm{L}$, potasu 2,82 mmol/L, chlorki $156 \mathrm{mmol} / \mathrm{L}$ (norma 96-106 mmol/L), wapń całkowity 7,3 mg/dL (norma 8,8-10,6 mg/dL).

Pacjentkę z rozpoznanym krwiakiem śródmózgowym, nieprzytomną, zaintubowaną, na oddechu wspomaganym, z podłączoną pompą infuzyjną, z podawanym lekiem thiopentalem przetransportowano do innego szpitala w celu zaopatrzenia w warunkach ostrego dyżuru neurochirurgicznego. Przy przyjęciu na oddział intensywnej terapii odnotowano, że pacjentka była niewydolna krążeniowo i oddechowo (konieczna były: intubacja, oddech kontrolowy, aminy katecholowe), ze wzrastającym ciśnieniem wewnątrzczaszkowym. Z uwagi na stan ogólny konsultujący neurochirurdzy nie zakwalifikowali pacjentki do zabiegu operacyjnego. W kontrolnych badaniach potwierdzono hipernatremię ( $180 \mathrm{mmol} / \mathrm{L}$ ) oraz hiperchloremię (152 mmol/L). W leczeniu stosowano preparaty: Mannitol, Natrium Bicarbonatrium, Biofazolin, Aldactan, Bicarbonat, $\mathrm{KCl}$, Tazocin, Calcium, Fentanyl, Pyralgin, Tetraspan, 5\% Glukoza z 16 jedn. Insuliny, a także Dopaminę i Levonor.

W następnym dniu przy postępującym pogorszeniu stanu zdrowia pacjentki wykonano badanie RTG klatki piersiowej, stwierdzając zapalenie płuc. W badaniach laboratoryjnych poziom sodu wahał się 180-191 mmol/L, a chlorków 140-156 mmol/L. Ciśnienie wewnątrzczaszkowe wzrosło z 18 do 80 , a także pojawiła się gorączka $38,8^{\circ} \mathrm{C}$.

W kolejnej dobie hospitalizacji stan pacjentki nie ulegał poprawie. Wysokie poziomy sodu i chlorków nadal się utrzymywały (odpowiednio 185 i $150 \mathrm{mmol} / \mathrm{L}$ ). W godzinach popołudniowych doszło do gwałtownego pogorszenia stanu chorej z załamaniem krążenia, co skutkowało jej zgonem. Za bezpośrednią przyczynę zgonu przyjęto masywne krwawienie podpajęczynówkowe, krwotok podostry płata skroniowego i jąder podstawy prawej półkuli mózgu oraz obrzęk mózgu, powikłane obustronnym zapaleniem płuc.

Z uwagi na okoliczności sprawy wszczęto śledztwo w sprawie nieumyślnego spowodowania śmierci 34-letniej kobiety (art. 155 k.k.). Analiza akt sprawy, w tym dokumentacji medycznej, pozwoliła biegłym na stwierdzenie, że najbardziej prawdopodobną przyczyną powstania krwiaków śródmózgowych były ciężkie zaburzenia elektrolitowe, za które odpowiada nie 
tylko spożycie przez 34-letnią kobietę kliku szklanek wody z dużą zawartością soli kuchennej, lecz także utrzymujący się przez kilka godzin nieleczony stan padaczkowy. Ponadto biegli sądowi z zakresu medycyny sądowej, toksykologii i neurologii w swojej opinii stwierdzili nieprawidłowości w postępowaniu lekarza A.Ch. w trakcie udzielania pomocy 34-letniej kobiecie, co naraziło ją na bezpośrednie niebezpieczeństwo utraty życia bądź ciężkiego uszczerbku na zdrowiu.

\section{DYSKUSJA}

Hipernatremia, czyli wzrost stężenia sodu w osoczu powyżej $148 \mathrm{mmol} / \mathrm{L}$, może być spowodowana utratą samej wody, niedostateczną podażą wody, nieprawidłową funkcją osmolatu w ośrodkowym układzie nerwowym czy nadmierną podażą sodu. Wspólna cecha wszystkich stanów chorobowych przebiegających z hipernatremią jest wzrost molarności płynów ustrojowych.

W hipernatremii wywołanej nadmierną podażą sodu dochodzi do hipertonii płynu pozakomórkowego warunkującego odwodnienie komórek (co skutkuje zmniejszeniem przestrzeni wodnej śródkomórkowej) oraz do równoczesnego zwiększenia przestrzeni wodnej pozakomórkowej. Zwiększa się stężenie substancji osmotycznie czynnych w płynie obu przestrzeni wodnych oraz ogólnoustrojowa zawartość sodu.

W hipernatremii ostrej, spowodowanej nadmierną podażą sodu, stwierdza się objawy uszkodzenia ośrodkowego układu nerwowego, które charakteryzują się zaburzeniami orientacji, omamami, wysoką gorączką, wzmożonym napięciem mięśni szkieletowych, drgawkami oraz śpiączką [4, 5, 6]. Badania autopsyjne wykazują krwotoki wewnątrzczaszkowe [5, 7].

W piśmiennictwie opisywany jest przypadek kobiety, której ratownicy medyczni podali 0,5 kg soli w $1500 \mathrm{~mL}$ wody w celu sprowokowania wymiotów. Pacjentka wypiła $1 \mathrm{~L}$ tak sporządzonego środka (330 g NaCl). Przy przyjęciu do szpitala pacjentka była pobudzona, bez kontaktu słowno-logicznego, a oznaczone stężenie sodu wynosiło $177 \mathrm{mmol} / \mathrm{L} \mathrm{i} \mathrm{chloru}$ $151 \mathrm{mmol} / \mathrm{L}$ [8]. Casavant i Fitch opisują zgon młodego mężczyzny, u którego stwierdzono hipernatremię (195 mmol/L) po spożyciu wody z solą [3].

W przedstawionym przypadku poziomy sodu (Na 180-191 mmol/L) i chlorków (Cl 140-156 mmol/L) były zbliżone do opisywanych w literaturze zgonów w wyniku hipernatremii $[1,3,8]$. Hipernatremia skutkowała wystąpieniem ciężkich zaburzeń gospodarki wodno-elektrolitowej, a następnie mnogich krwiaków wewnątrzczaszkowych prowadzących ostatecznie do zgonu. Mając na uwadze dane z wywiadu wskazujące na przyjęcie dużej ilości roztworu soli kuchennej przyjęto, że powstanie tych zmian w ośrodkowym układzie nerwowym wynikało m.in. ze znacznego odwodnienia tkanki mózgowej, co spowodowało pęknięcie drobnych wewnątrzkomórkowych naczyń krwionośnych. Brak zmian urazowych w obrębie powłok czaszkowych i kości czaszki wykluczył w przedstawionym przypadku możliwość urazowej przyczyny krwawień wewnątrzczaszkowych, które mogą również powodować wystąpienie zaburzeń elektrolitowych z hipernatremią włącznie.

W piśmiennictwie przedstawiono schematy postępowania medycznego, dzięki którym dochodzi do wyrównania hipernatremii. W tym celu stosowane są roztwory glukozy, hipotoniczne roztwory chlorku sodu $(0,45 \% \mathrm{NaCl})$ lub ich kombinacje [3, 9, 10, 11]. Wiśniewski i wsp. podają, że w przypadku pacjentów z hipernatremią można zastosować 5\% roztwór glukozy z jednoczesną dożylną podażą insuliny i chlorku potasu w celu uniknięcia hiperglikemizacji oraz hipokalemii [8].

W opisywanym przypadku, pomimo wielokrotnego odnotowania w badaniach laboratoryjnych wysokich stężeń sodu (191 mmol/L) oraz chloru (do $151 \mathrm{mmol} / \mathrm{L}$ ), aż do zgonu pacjentki nie rozpoznano ostrej hipernatremii, nie wdrożono również typowego dla tego stanu postępowania terapeutycznego. Podkreślić należy, że w czasie hospitalizacji pacjentce podawano preparaty soli fizjologicznej, co dodatkowo wpływało na pogorszenie jej stanu zdrowia.

\section{WNIOSEK}

Opisany przypadek wskazuje na wciąż istniejący brak należytej świadomości w kwestii przyczyn i następstw ostrych zaburzeń gospodarki wodno-elektrolitowej, jakie mogą być skutkiem błędnych prób leczenia ostrych zatruć.

\section{PIŚMIENNICTWO}

1. Ofran Y, Lavi D, Opher D, Weiss TA, Elinav E. Fatal voluntary salt intake resulting in the highest ever documented sodium plasma level in adults (255 mmol L-1): a disorder inked to female gender and psychiatric disorders. J Intern Med 2004;256(6):525-8. doi: 10.1111/j.13652796.2004.01411.x.

2. Ward DJ. Fatal hypernatremia after a saline emetic. Br Med J 1963;2:432.

3. Casavant MJ, Fitch JA. Fatal hypernatremia from saltwater used as an emetic. J Toxicol Clin Toxicol 2003;41(6):861-3.

4. Türk EE, Schulz F, Koops E, Gehl A, Tsokos M. Fatal hypernatremia after using salt as an emetic - report of three autopsy cases. Leg Med (Tokyo) 2005;7(1):47-50. doi: 10.1016/j.legalmed.2004.06.005.

5. Furukawa S, Takaya A, Nakagawa T, Sakaguchi I, Nishi K. Fatal hypernatremia due to drinking a large quantity of shoyu (Japanese soy sauce). J Forensic Leg Med 2011;18(2):91-2. doi: 10.1016/j.jflm.2010.11.011.

6. Addleman M, Pollard A, Grossman RF. Survival after severe hypernatremia due to salt ingestion by an adult. Am J Med 1985;78(1):176-8.

7. Yamazaki M, Terada M, Mitsukuni Y, Matoba R. An autopsy case of salt poisoning from drinking a large quantity of shoyu (Japanese soy sauce). Leg Med (Tokyo) 2000;2(2):84-7.

8. Wiśniewski M., Waldman W., Sein Anand J. Jatrogenna hipernatremia opis dwóch przypadków. Przegl Lek 2011;68(8):557-9.

9. Adrogué HJ, Madias NE. Hypernatremia. N Engl J Med 2000;342(20):1499. doi: 10.1056/NEJM200005183422006.

10. Aiyagari V, Deibert E, Diringer MH. Hypernatremia in the neurologic intensive care unit: how high is too high? J Crit Care 2006;21(2):163-72. doi: 10.1016/j.jcrc.2005.10.002.

11. Liamis G, Haralampos J, Elisaf M. A review of drug induced hypernatraemia. NDT Plus 2009;2(5):339-46. doi: 10.1093/ndtplus/sfp085. 